\title{
Bilateral Pulmonary Embolism Presenting as Lung Abscess in a Tuberculosis Patient: A Rare Presentation
}

\author{
Naveen Kuzhikkattil, Anil Saxena, Suman Khangarot, Shinu Abdul Wahab \\ Department of Respiratory Medicine, Government Medical College, Kota, Rajasthan, India
}

\section{Abstract}

Pulmonary embolism is a life-threatening medical emergency associated with high mortality and morbidity which is likely to be missed if a high index of suspicion is not maintained. Classical triad of chest pain, dyspnea, and hemoptysis is seen only in a minority of cases. Both inherited and acquired conditions are involved in its etiology. A case of bilateral pulmonary embolism presenting as lung abscess in a 65-year-old female with active tuberculosis is being discussed here.

Keywords: Acquired, inherited, life-threatening, triad

\section{INTRODUCTION}

Tuberculosis (TB) is a major public health problem worldwide since time immemorial, and India contributes about a quarter of the cases. Pulmonary embolism is common in a patient with prolonged immobility, congestive heart failure, recent surgery, systemic hypertension, atherosclerosis, old age, malignancy, nephrotic syndrome, and use of oral contraceptives by females. Rarely, TB can also predispose to it. Present or past episodes of deep-vein thrombosis (DVT) play a very important role in the development of pulmonary embolism. Lung abscess usually occurs secondary to aspiration and periodontal disease with anaerobic and Gram-negative organisms mainly involved in its etiology. Rarely can it be the presentation of pulmonary embolism.

\section{Case Report}

A 65-year-old female presented to the outpatient department with a history of fever, breathlessness, central chest pain, and swelling in bilateral lower limbs of 1-month duration, confining her to bed. Her husband had also taken one episode of treatment for pulmonary TB. No history of diabetes, hypertension, dyslipidemia, malignancy, or coronary heart disease was present. She had undergone one episode of anti-TB treatment for microbiologically confirmed pulmonary TB for 6 months from revised national tuberculosis control program (RNTCP) 2 years back and

\begin{tabular}{|l|l|}
\hline \multicolumn{2}{|c|}{ Access this article online } \\
\hline Quick Response Code: & Website: \\
\hline & www.ijrconline.org \\
\cline { 2 - 2 } & \\
\hline
\end{tabular}

was declared cured. She had no history of any surgery in the recent past and had attained her menopause 20 years back. On examination, the patient was cyanosed and bilateral pitting pedal edema was present along with engorgement of neck veins. Tachycardia was present (PR $-118 \mathrm{bpm})$ along with tachypnea (RR $-26 / \mathrm{min})$. Blood pressure was normal (104/72) and oxygen saturation was low $\left(\mathrm{SpO}_{2}-58 \%\right.$ without oxygen). Amphoric breath sounds were present in the right infraclavicular area with a dull note on percussion along with rib crowding and other features of volume loss. Chest X-ray showed a homogeneous opacity on the right side with a horizontal fluid level and fibrotic changes in the left upper lobe with infiltrates in the left lower lobe [Figure 1], and there was marked progression from her previous chest X-rays which warranted for a contrast-enhanced computed tomography (CT) of the thorax. Routine blood investigations were done. Complete blood count, renal function tests, random blood sugar, serum uric acid, fasting lipid profile, and serum electrolytes were within normal limits. Serum albumin level was decreased $(2.4 \mathrm{~g} / \mathrm{dl})$ and the total leukocyte

Address for correspondence: Dr. Naveen Kuzhikkattil, Room No. 225, PG Hostel 2, New Medical College Hospital, Rangbari Road, Kota - 324 005, Rajasthan, India. E-mail: naveengopikrishnan22@gmail.com

This is an open access journal, and articles are distributed under the terms of the Creative Commons Attribution-NonCommercial-ShareAlike 4.0 License, which allows others to remix, tweak, and build upon the work non-commercially, as long as appropriate credit is given and the new creations are licensed under the identical terms.

For reprints contact: reprints@medknow.com

How to cite this article: Kuzhikkattil N, Saxena A, Khangarot S, Wahab SA. Bilateral pulmonary embolism presenting as lung abscess in a tuberculosis patient: A rare presentation. Indian J Respir Care 2020;9:94-6.

Received: 24-02-2019

Accepted: 15-05-2019
Revised: 14-04-2019

Published: 08-01-202 
count was 8800 . Screening for HIV and hepatitis B surface antigen was negative. Sputum acid-fast bacillus staining and pyogenic culture were negative. Sputum was sent for cartridge based nucleic acid amplification test (CBNAAT), and Mycobacterium tuberculosis was detected which was sensitive to rifampicin. Electrocardiogram revealed sinus tachycardia with right ventricular hypertrophy and $\mathrm{P}$ pulmonale [Figure 2]. CT of the thorax revealed acute pulmonary embolism in both the pulmonary arteries (right $>$ left) with pulmonary hypertension along with dilated right and left ventricles and right lung abscess with significant volume loss in the right side and fibrocalcific opacities with traction bronchiectasis and collapse of the left upper lobe and tree in bud opacities in the left lower lobe suggestive of active infection [Figure 3]. Two-dimensional echocardiography, protein $\mathrm{C}$, protein $\mathrm{S}$, antithrombin III, and antiphospholipid antibodies could not be analyzed due to the economic constraints of the patient and limitation of investigations in our laboratory. Serum C-reactive protein (CRP) was negative and Doppler study of bilateral lower limbs was within normal limits.

$\mathrm{O}_{2}$ therapy was initiated following which her saturation improved. The patient was started on anti-TB chemotherapy and low-molecular-weight heparin followed by warfarin. There was no indication for thrombolysis. Antibiotics with Gram-negative and anaerobic coverage were started. Bronchodilators, antipyretics, and diuretics were given for symptomatic relief.

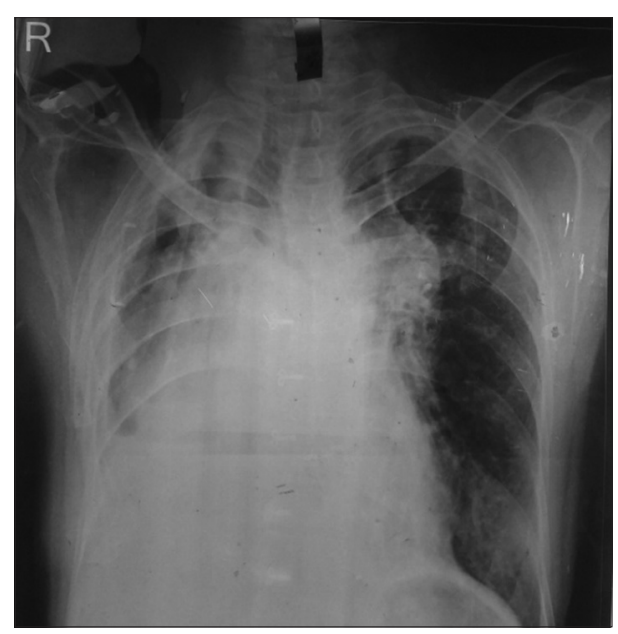

Figure 1: Chest $\mathrm{X}$-ray posteroanterior view showing bilateral lung lesion

\section{Discussion}

Association of pulmonary embolism with $\mathrm{TB}$ is a rare occurrence, and only a few cases are reported in the literature. DVT confirmed by venography has been observed in $3 \%-4 \%$ of patients with pulmonary $\mathrm{TB},{ }^{[1]}$ and one-third of these manifests as pulmonary embolism. Death occurs in $12 \%$ of pulmonary embolism cases within 1 month of diagnosis. ${ }^{[2]}$ Factors responsible for the development of thromboembolism are still unclear. All the three elements of Virchow's triad, namely hypercoagulability, venous stasis, and endothelial dysfunction, seem to be operational in the development of pulmonary embolism. Infections such as TB can rarely lead to thromboembolism by enhancing platelet aggregation; increasing fibrinogen, fibrin degradation products, plasminogen activator inhibitor and through associated deficiencies of protein C, protein S and antithrombin III. ${ }^{[3,4]}$ Rifampicin is also implicated in the increased incidence of DVT in a study. ${ }^{[5]}$ Pro-inflammatory cytokines released during the disease can make the endothelium more thrombogenic and also enhance synthesis of clotting factors by the liver ${ }^{[6,7]}$ Enlarged lymph nodes compressing the veins can also lead to thrombosis. ${ }^{[8]}$ High frequency of antiphospholipid antibodies detected in patients with TB has also been mentioned in the literature. CRP has been implicated in platelet aggregation associated with TB. Pulmonary infarction is seen in only 10 percent of the cases of pulmonary embolism due to the dual nature of blood supply. ${ }^{[9]}$ Aseptic liquefaction and cavitation occur in infarcts $>4 \mathrm{~cm}$ in size. ${ }^{[10]}$ Cavitation occurs in about $4 \%-7 \%$ cases of pulmonary infarction, ${ }^{[1]]}$ in which superinfection with anaerobic and Gram-negative organisms can occur.

Antituberculous chemotherapy (ATT) and anticoagulant therapy should be started at the earliest, and coagulation abnormalities associated with TB will be corrected within about 12 weeks. Rifampicin may interfere with the action of oral anticoagulants such as warfarin by inducing cytochrome $\mathrm{P} 450$, thereby reducing its efficacy close to $50 \%$.

\section{Conclusion}

A high index of suspicion should be maintained for diagnosis of pulmonary embolism at the earliest, as it is associated with a very high mortality rate. Anticoagulant therapy should be instituted, and thrombolysis should be considered in patients with hemodynamic instability. Surgical embolectomy is another feasible option in well-equipped centers.

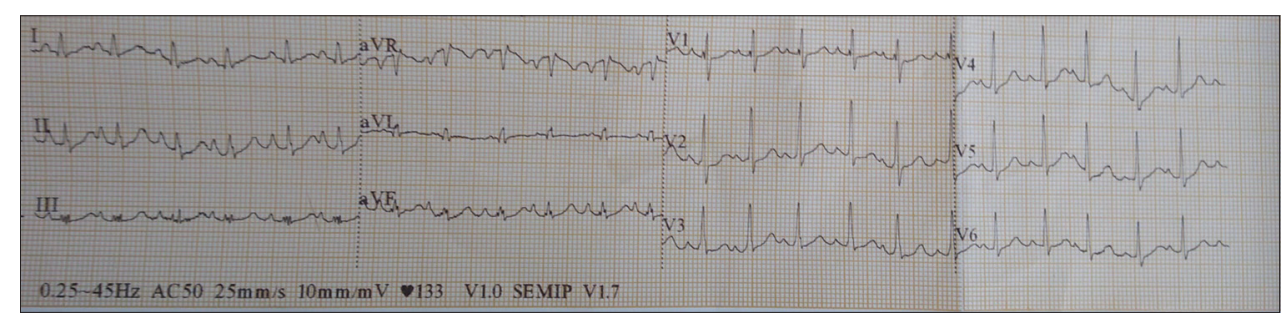

Figure 2: Electrocardiogram showing sinus tachycardia with right ventricular hypertrophy and P pulmonale 
Kuzhikkattil, et al.: Bilateral pulmonary embolism

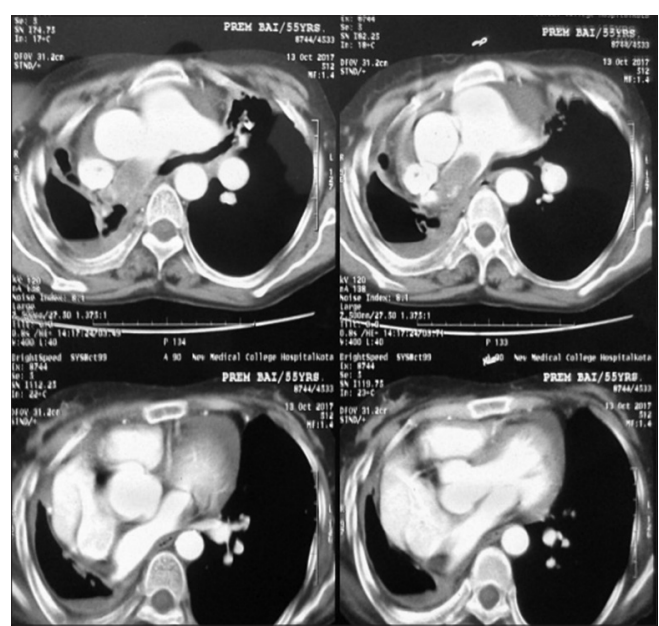

Figure 3: Contrast-enhanced computed tomography of the thorax demonstrating filling defect and cavitation with air-fluid level

\section{Financial support and sponsorship}

Nil.

\section{Conflicts of interest}

There are no conflicts of interest.

\section{REFERENCES}

1. Cowie RL, Dansey RD, Hay M. Deep-vein thrombosis and pulmonary tuberculosis. Lancet 1989;2:1397.

2. Heit JA, O'Fallon WM, Petterson TM, Lohse CM, Silverstein MD, Mohr DN, et al. Relative impact of risk factors for deep vein thrombosis and pulmonary embolism: A population-based study. Arch Intern Med 2002;162:1245-8.

3. Sarode R, Bhasin D, Marwaha N, Roy P, Singh K, Panigrahi D, et al. Hyperaggregation of platelets in intestinal tuberculosis: Role of platelets in chronic inflammation. Am J Hematol 1995;48:52-4.

4. Turken O, Kunter E, Sezer M, Solmazgul E, Cerrahoglu K, Bozkanat E, et al. Hemostatic changes in active pulmonary tuberculosis. Int J Tuberc Lung Dis 2002;6:927-32.

5. Morris CD, Bird AR, Nell $\mathrm{H}$. The haematological and biochemical changes in severe pulmonary tuberculosis. Q J Med 1989;73:1151-9.

6. Mark PL, Ashok PP, Deshpande RB, Mahashur AA. A patient with hypercoagulable state due to tuberculosis. Indian J Chest Dis Allied Sci 2009;51:49-51.

7. Andus T, Bauer J, Gerok W. Effects of cytokines on the liver. Hepatology 1991;13:364-75.

8. Gogna A, Pradhan GR, Sinha RS, Gupta B. Tuberculosis presenting as deep vein thrombosis. Postgrad Med J 1999;75:104-5.

9. Fishman AP, Elias JA, Fishman JA, Grippi MA, Senior RM, Pack AI, editors. Fishman's Pulmonary Diseases and Disorders. $4^{\text {th }}$ ed. New York: McGraw-Hill; 2008.

10. Wilson AG, Joseph AE, Butland RJ. The radiology of aseptic cavitation in pulmonary infarction. Clin Radiol 1986;37:327-33.

11. Libby LS, King TE, LaForce FM, Schwarz MI. Pulmonary cavitation following pulmonary infarction. Medicine (Baltimore) 1985;64:342-8. 